\title{
Improving factory layout under a mixed floor and overhead material handling condition
}

\author{
Manocher Djassemi \\ Industrial Technology Area of Orfalea College of Business, \\ California Polytechnic State University, San Luis Obispo, California, USA
}

\begin{abstract}
Purpose - In spite of having a number of general-purpose algorithms for solving plant layout problems, facility planners may still face a challenging task to adjust these algorithms to handle special, but not uncommon, layout problems. The purpose of this study is to propose a new method for addressing the impact of overhead space utilization on a plant layout solution.

Design/methodology/approach - A new method for adjusting material flow under a mixed floor and overhead material handling condition is incorporated in an existing plant layout procedure. A case study involving the layout improvement in a lawn mower engine assembly facility is presented to illustrate the effectiveness of the proposed method.

Findings - The analysis of solutions for the case study shows that the layout generated by the proposed modified material flow approach is a more economical solution. The case also shows, when it is important to optimize the use of space, the overhead space should be considered as part of any methodology for designing a good layout.

Research limitations/implications - The proposed modified material flow approach can be applied to any facility where the use of overhead space for material handling is justifiable by limited floor space and/or by high cost of land. The proposed method can be applied to small to medium size problems with minimal computational effort. However, as the size of facility grows, the manual calculation becomes more time consuming and potentially erratic.

Originality/value - This paper should be useful to both researchers and practitioners who deal with overhead space utilization in designing facility layouts.
\end{abstract}

Keywords Facilities, Plant layout, Materials handling

\section{Introduction}

The efficiency of a manufacturing facility depends on a number of factors, including the layout of machinery and departments. Typical plant layout procedures determine how to arrange the various machines and departments to achieve minimization of overall production time, maximization of turnover of work-in-process, and maximization of factory output.

A number of procedures have been developed to aid facilities planners in designing new layouts or improving existing layouts. Meller and Gau (1996) listed more than 90 published layout models and algorithms. These layout algorithms are based on two types of objective functions: distance-based and adjacency-based. The common parameters in these objective functions are interdepartmental flow, $f_{i j}$; unit-cost values, $c_{i j}$; distance between departments, $d_{i j}$; and department closeness rating, $x_{i j}$. A distance-based objective function aimed at minimizing distance between departments is expressed mathematically as: 


$$
\operatorname{Min} Z=\sum_{i=1}^{m} \sum_{j=1}^{m} f_{i j} c_{i j} d_{i j}
$$

One of the distance-based layout algorithms is MULTIPLE (Bozer and Meller, 1997) in which improvement to layout is sought through a two-way exchange, and at each iteration the exchange that leads to the largest reduction in layout cost is selected. LOGIC uses quantitative flow data and divides the layout into smaller portions by successive horizontal or vertical straight cuts, and then departments are placed left, right, above, or below the cuts based on the associated cost (Tam, 1991).

Algorithms developed according to the adjacency-based objective function are intended to maximize the adjacency score, which is computed as the sum of all flow values between those departments that are adjacent in the layout. The objective function is expressed mathematically as:

$$
\operatorname{Max} Z=\sum_{i=1}^{m} \sum_{j=1}^{m} f_{i j} x_{i j}
$$

The graph theory method (Seppannen and Moore, 1970) is an adjacency-based objective function method in which each department is represented by a node in a graph. A satisfied department adjacency relationship is presented by an arc connecting the two adjacent departments (nodes) in the graph. The objective is to construct a layout to maximize the sum of arc weights, to maximize the weight on the adjacencies between department pairs.

In addition to the aforementioned heuristic methods, a number of mathematical and stochastic-based algorithms for solving a facility layout problem have been proposed in the literature, including genetic algorithms (GA). GA explore the solution space by using concepts taken from genetics and evolution theory (Tavakkoli and Shayan, 1997). One recent version of the GA approach (Adel El-Baz, 2004) determines the optimal layout for different material flow systems, which minimizes the total material handling $(\mathrm{MH})$ cost. Azadivar and Wang (2000) proposed a GA approach combined with simulation modeling to develop a layout design technique that not only considers minimal MH cost, but also emphasizes on other performance measures such as production rates and cycle times.

Some algorithms determine departmental closeness ratings based on qualitative data; others convert quantitative flow data to closeness rating values. BLOCPLAN (Donaghey and Pire, 1990) uses an activity relationship chart as well as a From-To chart as input data for the material flow. It considers all possible two-way or three-way department exchanges in a number of iterations until the layout with minimum objective function cost is obtained. Systematic layout planning (SLP) is a procedure based on an activity relationship chart and material flow analysis (Muther, 1973). Departments are graphically placed as close to each other as possible, depending on the value of the closeness rating, which is based on material flow intensity and/or practical factors such as environmental and safety factors.

The foregoing algorithms represent a sample of existing plant layout methods. These and other methods are designed for general-purpose applications and may not be effective tools for solving layout problems in certain cases. The case addressed in this study considers material transfers by both floor and overhead types of carriers. 
In this case, the principle of minimization of material flow may not be a desirable objective for every material move within the facility because the overhead space is used as a means to maximize facility space utilization and as a buffer zone to balance the workload among departments. It is fair to say that without taking the overhead space utilization factor into consideration, the deployment of any plant layout procedure may result in a layout solution that could perform far below an optimal level. There is little or no discussion about this issue in published works. The closest studies that can be found in the literature are those which address the problem of multi-floor layout design. For example, Patsiatzis and Papageorgiou (2002) presented a general mathematical formulation for the multi-floor plant layout problem with the objective of determining the number of floors, land area, optimal equipment-floor allocation with minimal total plant layout cost. A similar research has been conducted by Matsuzaki et al. (1999) which presented an algorithm to get a solution of the layout problem for multiple floors by incorporating elevators for material handling.

In this study we propose a procedure for dealing with mixed floor and overhead material flows in existing facilities. To demonstrate the effectiveness of the proposed approach, a case study involving a major lawn mower engine assembly facility is presented.

\section{Modified material flow procedure}

In general, there is strong relationship between the amount of material flow and the proximity of departments when one of the facility planning procedures is deployed. That is, the larger the amount of flow between two departments, the closer they are positioned to each other. In addition to material flow data, other factors such as environmental factors, building constraints, and/or the MH system configuration may play a critical role in attaining a practical solution.

As mentioned earlier, the issue of overhead space utilization and its trade-off with interdepartmental distances has not been addressed in the literature. Most existing procedures aim at placing departments as close as possible to each other due to significant material flow and regardless of whether the material is transported by floor equipment or by overhead equipment. However, when the overhead space utilization is considered, the material flow should not have the same impact on determining the closeness of the departments. This is due to the fact that using overhead space can be beneficial in that, first, it plays the role of a buffer zone for holding parts while the materials are in transit, and second, the overhead space can balance the workload between departments. Therefore, to reflect the impact of overhead space utilization in the final layout, it is necessary to adjust the material flow data such that it would not cause the departments on the two ends of a particular travel path to be placed so close to each other that the benefit of overhead space utilization is undermined.

In view of above discussion, a cost-based modified material flow (MMF) measure is defined as:

$$
\mathrm{MMF}_{\text {cost }(i j)}=R_{i j} U_{\text {overhead }(i j)}
$$

Where $U_{\text {overhead(ij) }}$ represents the overhead material flow volume in unit loads between departments $i$ and $j . R_{i j}$ is a weighting factor that represents the ratio of the operational cost of moving materials between departments $i$ and $j$ by overhead equipment to the operational cost of moving the same volume of materials by floor equipment in a hypothetical scenario: 


$$
R_{i j}=\frac{L_{i j} C_{\mathrm{OH}}}{D_{\mathrm{FL}(i j)} C_{\mathrm{FL}}} .
$$

where, $L_{i j}$ actual length of overhead $\mathrm{MH}$ equipment between departments $i$ and $j$; $C_{\mathrm{OH}}$ operating cost of overhead $\mathrm{MH}$ equipment per foot per part; $D_{\mathrm{FL}(i)}$ distance between departments $i$ and $j$ if material were moved by a floor material handler; $C_{\mathrm{FL}}$ operating cost of moving material by a floor material handler per foot per part.

In equation (4), a number of factors have been considered, including the cost of operating overhead and floor $\mathrm{MH}$ equipment, the length of overhead $\mathrm{MH}$ equipment such as monorails or trolleys, and the distance between departments.

By using $R_{i j}$ factor in equation (3), the actual material flow, $U_{\text {overhead, }}$ is intentionally increased or deceased. For example, if the operational cost of using of fork lift truck is less than the cost of using an overhead conveyor, then $R_{i j}>1$ and as a result, the modified material flow, MMF, would be higher than the actual material flow between the two involved departments. This intentional increase in material flow volume may result in positioning the two departments closer to each other, which translates to less utilization of overhead space. In this example, it is obvious that the use of a fork lift truck is more economical than using an overhead conveyor.

Next, the effect of utilization of overhead $\mathrm{MH}$ equipment is taken into consideration by modifying the equation (1) as follows:

$$
\mathrm{MMF}_{\text {overall }(i j)}=\left[R_{i j}+\left(1-\mathrm{Ut}_{i j}\right)\right] U_{\text {overhead }(i j)}
$$

where $\mathrm{Ut}_{i j}$ represents the historical utilization of overhead $\mathrm{MH}$ equipment between department $i$ and $j$ :

In equation (5), the overall modified material flow, MMF, would not be affected at $\mathrm{Ut}_{i j}=1.0$. As the utilization of overhead MH equipment decreases the MMF decreases accordingly. The impact of such intentional adjustment is that the reduced flow volume would not be as significant as actual flow volume between departments $i$ and $j$. Consequently, the two departments may be positioned farther apart for the sake of enhanced use of the space above them.

The algorithmic form of a procedure for applying modified material flow, MMF, to an existing plant layout problem is as follows:

(1) determine the number of unit loads (pallets, baskets, or boxes) for floor material flow;

(2) for material flow moved by an overhead $\mathrm{MH}$ device, determine the equivalent unit loads in number of pallets or baskets $\left(U_{\text {overhead }(i j)}\right)$;

(3) determine the adjusted material flow using equation (5);

(4) set up a From-To chart that includes unit loads for floor and overhead moves as well as modified unit loads for overhead moves;

(5) use the From-To chart generated in step 4 as input to one of the available plant layout methods to generate two layout alternatives,with and without material flow data modification; and

(6) compare the performance of the alternative layouts.

The proposed modified material flow procedure will be applied to the layout of a lawn mower engine assembly plant, as described below. 


\section{Case study}

The facility under study is a manufacturing and assembly plant that produces internal combustion engines in various sizes for lawn movers. The plant produces over three millions engines a year. The under roof facility encompasses 300,000 square feet, operates ten different shops and two assembly lines in two shifts.

Currently parts are transferred by various $\mathrm{MH}$ equipment including manual trucks, power fork lift trucks, conveyors and overhead trolleys. It appeared that the combination of overhead and floor $\mathrm{MH}$ methods in this facility, created an environment suitable for application of modified material flow procedure proposed in this study.

The examination of the parts lists revealed that there are more than 200 components used in the assembly of a typical lawn mower engine. Furthermore, more than 80 percent of the parts are imported from various vendors and the remainder are fabricated in-house. It was also noted that only 5 percent of the components account for 90 percent of the $\mathrm{MH}$ activities. Table I shows the daily volume of material flow and the type of $\mathrm{MH}$ equipment for the components with the highest material flow. Figure 1 shows the current layout of the facility along with the material flow diagram. The broken and solid arrows indicate overhead and floor material flow, respectively.

Following the six-step procedure described previously, adjusted unit loads, $\mathrm{MMF}_{\text {overall, }}$, are calculated for the flow between a number of departments where overhead material handlers are deployed. Table II shows a list of these departments as well as data required for calculating $\mathrm{MMF}_{\text {overall }}$ values. In determining cost data for overhead material handlers and fork lift trucks, a number of factors are taken into consideration, including electricity consumption, maintenance, and labor costs.

The distance between departments is determined as follows: the distance traveled along the aisles for floor material handlers and the actual length of monorails for overhead material moves.

\begin{tabular}{lll}
\hline Part name & Unit load size & MH device \\
\hline Cylinder & Continuous & Overhead conveyor \\
Cylinder head & $900 /$ basket & Lift truck/overhead conveyor \\
Engine sump & 225/basket & Lift truck/overhead conveyor \\
Crankshaft & 150/box & Lift truck/overhead conveyor \\
Camshaft & 150/box, 12 Box/pallet & Lift truck \\
Connecting rod & 2,750/basket & Lift truck \\
Piston & 2,100/basket & Lift truck \\
Flywheel & 560/basket & Lift truck \\
Carburetor & 250/box & Lift truck \\
Fuel tank top & $1,200 /$ basket & Lift truck \\
Fuel tank bottom & 300/basket & Lift truck \\
Muffler & 300/basket & Lift truck \\
Air cleaner & 800/basket & Lift truck \\
Flywheel guard & $9,000 /$ basket & Lift truck \\
Control bracket & 500/basket & Lift truck \\
Blower housing & Continuous & Overhead conveyor \\
Blower housing cover & 250/basket & Lift truck \\
Finished engine & 140/pallet & Lift truck \\
\hline
\end{tabular}

Table I.

Engine parts list and related materials handling information 
Figure 1.

Existing layout and material flow diagram

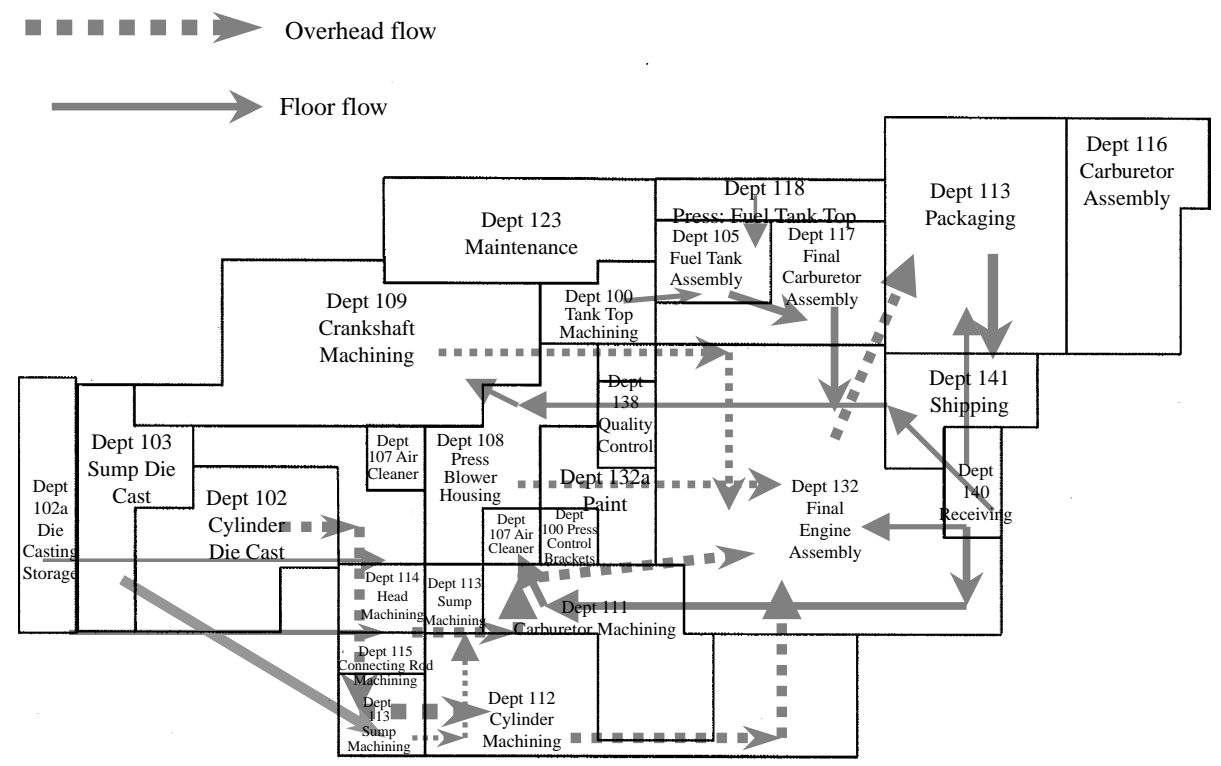

The lengths of overhead monorails and trolleys were accurately measured using available CAD data. Figure 2 shows a From-To chart that consolidates flow volumes for all materials transferred by floor and overhead equipment.

Next, the numerical flow data shown in the From-To chart is used as input to one of the common facility layout planning methods known as SLP, devised by Muther (1973). SLP is not only a proven tool in providing layout design guidelines, but it is also widely used among commercial enterprises and academic institutions (Yang et al., 2000). Based on SLP, closeness ratings of A, E, I, and O between the departments are generated and incorporated in the same chart. For the overhead transporters, the closeness ratings were determined based on corresponding $\mathrm{MMF}_{\text {overall(ii) }}$ values, and the results are shown in shaded boxes in Figure 2. Then, based on the ranking of closeness ratings, a spatial layout is developed indicating the relative location of departments. Finally, the spatial block layout is transformed into a layout that conforms to the actual boundary of the engine assembly facility.

Figures 3 and 4 show two alternative layouts developed using the SLP method: with and without flow adjustment. It is noteworthy to mention that in this facility most material flows are directed from various departments toward the final engine assembly line in department 132. Therefore, one can expect a good layout solution to reflect shorter distances between the main assembly line and almost all other departments. However, when the modified material flow approach was applied, a rather different solution was obtained. To this end, the following analysis can be made when the existing layout, and the two alternatives are compared:

- In both alternative layouts, diecasting departments remained next to each other at their current location on the left side of the engine assembly facility. This was due to the nature of the diecasting process and its high level of noise, heat, and fumes. 


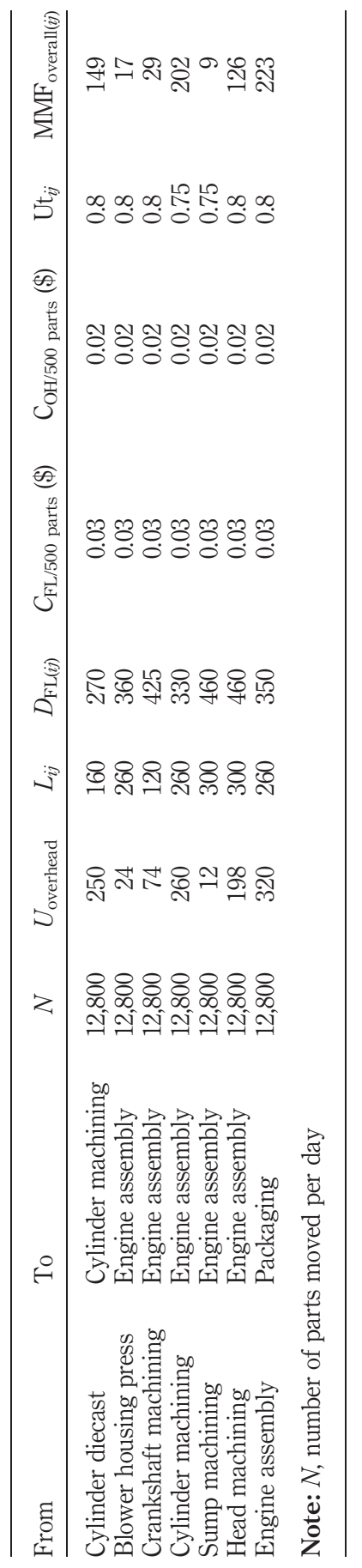

Table II.

Data for overhead material flow 
Figure 2.

From-To chart for engine assembly facility
Figure 3.

Improved layout without flow adjustment

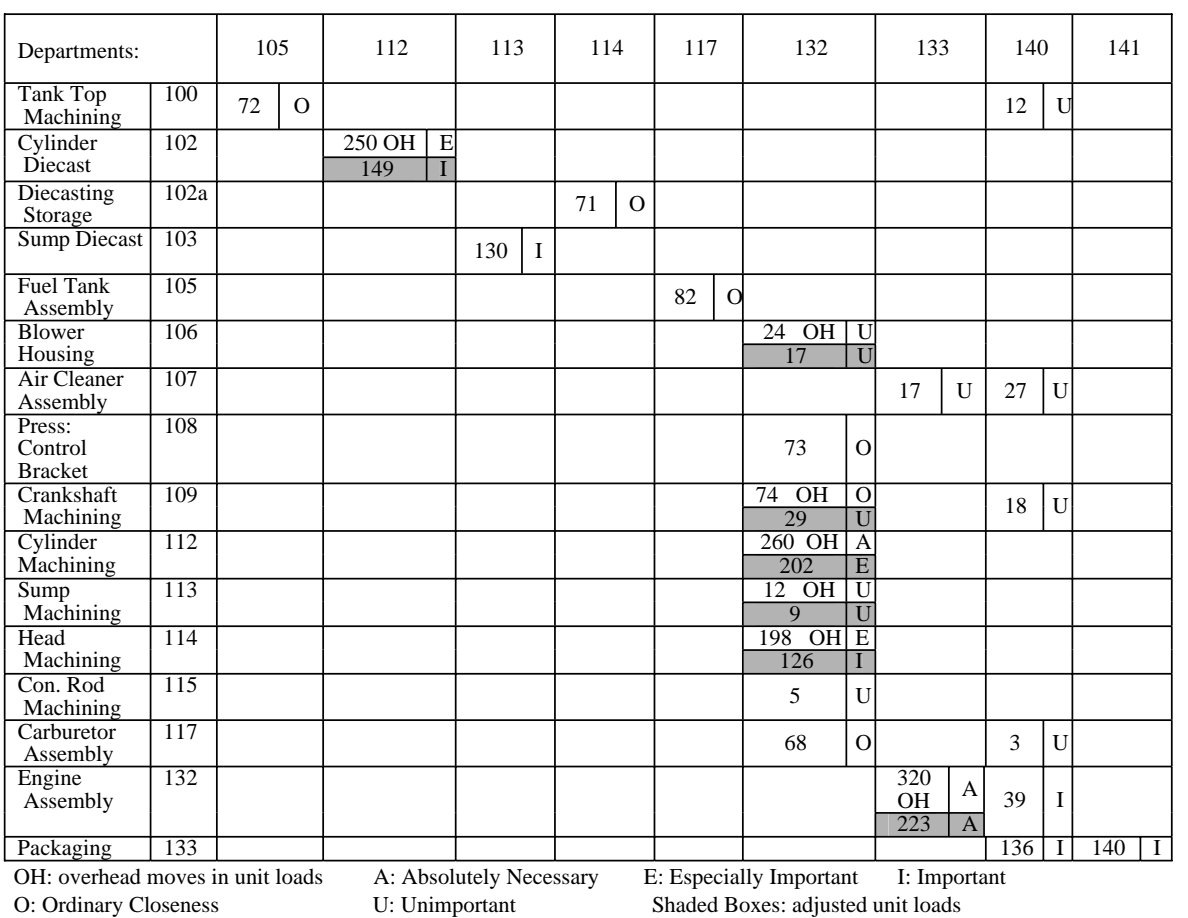

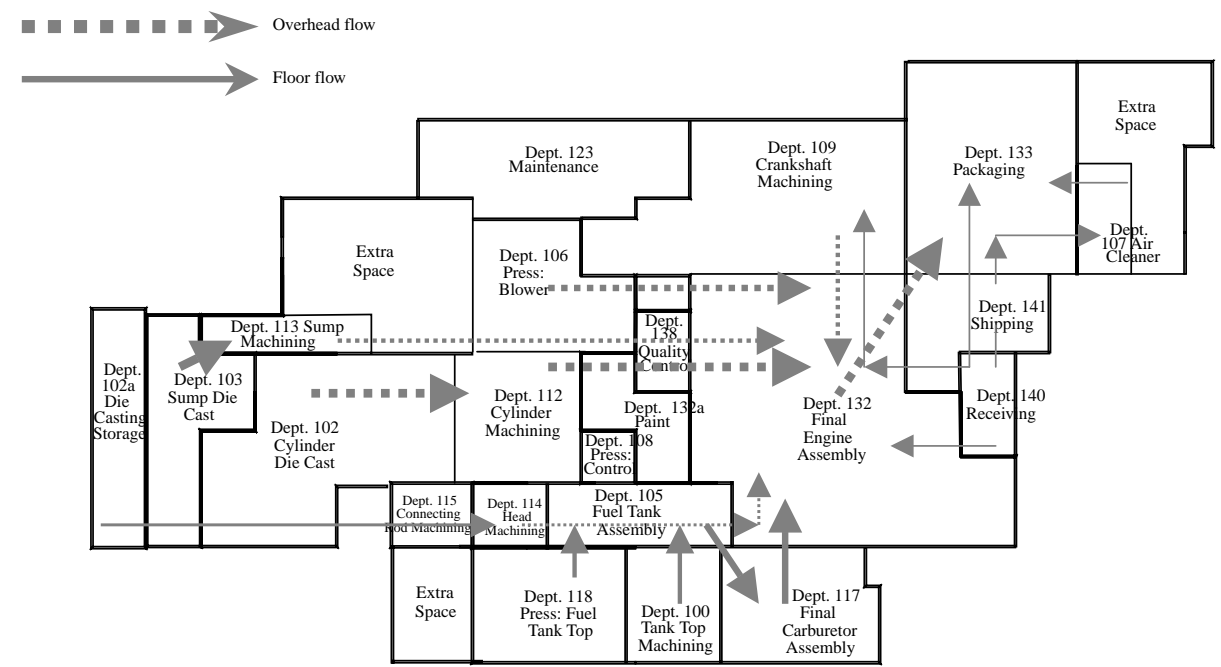

- The crankshaft machining department (No. 109) was moved in alternative (b) to the vicinity of the final assembly department (No. 132) due to the important (I) relationship between the two departments (Figure 3). However, when the adjusted flow approach was deployed, the closeness rating was downgraded to ordinary $(\mathrm{O})$. 
Figure 4.

Improved layout using

adjusted material flow

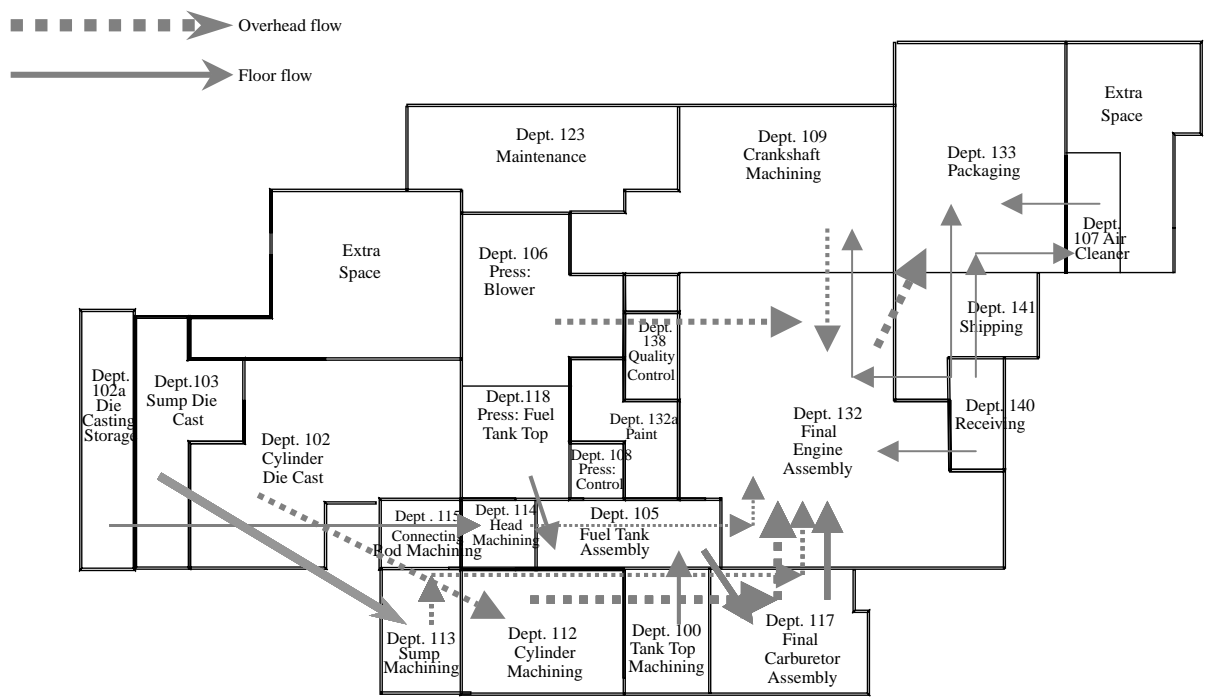

As a result, department 109 stayed at its current location in alternative (a), as shown in Figure 4. This change of relationship is due to the impact of overhead space utilization between the two departments. As can be seen in Figure 4, by keeping the crankshaft machining department at its current location, departments 100, 105, 117, and 118 did not have to be relocated as in alternative (b), saving a significant relocation cost.

- The blower housing press department (No. 106) has an (I) relationship with the final assembly department in alternative (b) and stayed at its current location. However, in alternative (a), department 106 had an (O) relationship with the final assembly department. Because this is an ordinary closeness rating, department 106 has been moved farther away from department 132, which in turn opens some space in the center of the facility so departments 102a and 114, which have (I) relationships can be positioned adjacent to each other.

Next, the original layout and the two alternatives are compared using the total operating cost (TOC) of overhead and floor MH equipment. TOC is expressed as follows:

$$
\mathrm{TOC}=\sum \sum C_{\mathrm{OH}} L_{i j}+\sum \sum\left(C_{\mathrm{FL}} D_{\mathrm{FL}(i j)}\right)
$$

where $\mathrm{C}_{\mathrm{OH}}, L_{i j}, C_{\mathrm{FL}}$, and $D_{\mathrm{FL}(i j)}$ are as previously defined.

Using the data in Table I and interdepartmental distances, the TOC for each of the three layouts are obtained as follows:

(1) TOC for the existing layout: $\$ 3096$

(2) TOC for alternative (a) (flow adjustment allowed): $\$ 2450$

(3) TOC for alternative (b) (flow adjustment not allowed): $\$ 2633$

Alternative (a) outperforms both the existing layout and alternative (b). Moreover, there are two disadvantages associated with alternative (b) that make it even less 
attractive. First, it prevents utilization of overhead space due to unnecessarily shorter distances between some departments. Second, there are extra costs associated with relocation of equipment. These conclusions were supported by the engineering staff of the facility who agreed that alternative (a) was superior to both the existing plan and alternative (b).

\section{Conclusion}

This paper described a procedure for incorporating overhead space utilization in existing plant layout algorithms using a modified material flow approach. The SLP method (Muther, 1973) was used as a means for to develop a solution methodology. The combined SLP and MMF procedure generates two solutions for improving the plant layout. The first solution is based on actual material flow data. The second solution is based on actual material flow data adjusted by a material flow factor, to account for overhead space utilization and associated MH costs.

In this study, the applicability of the proposed method has been demonstrated by a case study in a lawn mower engine assembly facility. The analysis of the two layout solutions showed that the layout generated by the modified material flow factor is a more economical solution. Clearly, a practical and economical layout is not always as straightforward as finding a layout with minimum travel distances or minimum $\mathrm{MH}$ costs. As this case study shows, when it is important to optimize the use of space, the overhead space should be considered as part of any methodology for designing a good layout.

The proposed MMF approach can be applied to any plant layout problem where the use of overhead space for material handling is justifiable by limited floor space and/or by high cost of land. The proposed method can be also applied manually to small to medium size problems with minimal computational effort. However, as the size of facility and the number of departments grow, the manual calculation becomes more time consuming and potentially erratic. To overcome such limitation and as an extension to this study the proposed MMF approach can be incorporated in a facility planning software such as BLOCPLAN or FactoryPLAN. Another interesting extension to this study would be to investigate how the other plant layout procedures such as LOGIC or MULTIPLE perform under similar conditions where a mixed floor and overhead flow exist.

\section{References}

Adel El-Baz, M. (2004), "A genetic algorithm for facility layout problems of different manufacturing environments”, Computers \& Industrial Engineering, Vol. 47 No. 2, pp. 233-46.

Azadivar, F. and Wang, J. (2000), "Facility layout optimization using simulation and genetic algorithms", International Journal of Production Research, Vol. 38 No. 17, pp. 4369-83.

Bozer, Y.A. and Meller, R.D. (1997), "A reexamination of the distance-based facility layout problem”, IIE Transactions, Vol. 29 No. 7, pp. 549-60.

Donaghey, C.E. and Pire, V.F. (1990), Solving the Facility Layout Problem With BLOCPLAN, Industrial Engineering Department, University of Houston, Houston, TX.

Matsuzaki, K., Irohara, T. and Yoshimoto, K. (1999), "Heuristic algorithm to solve the multi-floor layout problem with the consideration of elevator utilization", Computers \& Industrial Engineering, Vol. 36 No. 2, pp. 487-502. 
Meller, R.D. and Gau, K.Y. (1996), "The facility layout problem: recent and emerging trends and perspectives", Journal of Manufacturing Systems, Vol. 15 No. 5, pp. 351-66.

Muther, R. (1973), Systematic Layout Planning, 2nd ed., Cahners Books, Boston, MA.

Patsiatzis, D.I. and Papageorgiou, L.G. (2002), "Optimal multi-floor plant layout”, Computers \& Chemical Engineering, Vol. 26 Nos 4/5, pp. 575-83.

Seppannen, J. and Moore, J.M. (1970), "Facilities planning with graph theory", Management Science, Vol. 17 No. 4, pp. 242-53.

Tam, K.Y. (1991), “A simulated annealing algorithm for allocating space to manufacturing Cells”, IJPR, Vol. 30, pp. 63-87.

Tavakkoli, R. and Shayan, E. (1997), "Facilities layout design by genetic algorithms", Proceeding of 22nd International Conference on Computer and Industrial Engineering, pp. 415-8.

Yang, T., Su, C.T. and Hsu, Y.R. (2000), "Systematic layout planning: a study on semiconductor wafer fabrication facilities", International Journal of Operations \& Production Management, Vol. 20 No. 11, pp. 1360-72.

\section{Further reading}

Sly, D.P. (1996), "A systematic approach to factory layout and design with FactoryPLAN, FactoryOPT, and FactoryFLOW", Proceedings of the 28th Conference on Winter Simulation, pp. 584-7. 